\title{
Do young people who are not in education, employment or training (NEET) have more health problems than their peers? A cross-sectional study among Norwegian adolescents
}

\author{
Tonje Holte Stea ${ }^{1}$, Eirik Abildsnes ${ }^{2}$, Arve Strandheim ${ }^{3}$ and Siri Håvås Haugland ${ }^{4}$ \\ 1) Faculty of Health and Sport Science, Department of Public Health, Sport and Nutrition, University of Agder, Kristiansand \\ 2) Kristiansand municipality, Norway and Department of Global Public Health and Primary Care, University of Bergen \\ 3) Regional Centre for Child and Youth Mental Health and Child Welfare, Norwegian University of Science and Technology and \\ Department of Child and Adolescent Psychiatry, Nord-Trøndelag Health Trust \\ 4) Faculty of Health and Sport Science, Department of Psychosocial Health, University of Agder, Kristiansand \\ Correspondence: Tonje Holte Stea, Faculty of Health and Sport Science, University of Agder, Service Box 422, NO-4604 Kristiansand, Norway \\ Email: tonje.h.stea@uia.no Telephone: +4738142324 Telefax:+4738141301
}

\begin{abstract}
Objectives: An increasing proportion of young Norwegians are categorised as too ill to attend upper secondary education, and poor physical and mental health may reduce their opportunities to return to school or find paid employment. This study examined the differences in self-perceived health, mental health, and prevalence of pain between Norwegian adolescents, who are not in education, employment or training (NEET) compared to adolescents who attend upper secondary school (age 16-21 years).

Design: Cross-sectional study.

Participants and setting: A total of 96 NEET youth and 384 age and gender matched adolescents attending upper secondary school in the south of Norway participated in the study.

Main outcome measures: Self-perceived health, mental health and pain.

Results: Multivariable analyses, adjusted for parental education, showed that more NEET girls reported poor self-perceived health (odds ratio $3.2 ; 95 \%$ CI $1.4-7.5)$ and poor mental health $(2.4 ; 1.0-5.2)$ when compared to girls who were attending school. The results showed no difference in the prevalence of various types of pain between girls who were attending or not attending school, and among boys the results showed no differences in health problems assessed in this study.

Conclusion: The study indicates that NEET girls have poorer self-perceived health and poorer mental health when compared to girls who are attending upper secondary school. It will be essential to identify the causes of these health problems. This may provide a basis for specially adapted measures that could help more people in the target group return to school or paid employment.
\end{abstract}

This is an open access article distributed under the Creative Commons Attribution Licence, which permits unrestricted use, distribution, and reproduction in any medium, provided the original work is properly cited.

\section{INTRODUCTION}

Health problems may increase the risk of school dropout $[1,2]$. However, a Norwegian prospective study also found that school dropouts have increased risk of long-term sickness and disability irrespective of previous health problems in adolescence [3]. Social exclusion may lead to the development or worsening of health problems, and this may in turn preserve people in a marginalized situation [4-6]. Few studies, however, have examined health problems among young people who were not in employment, education or training (NEET). The present study will therefore contribute to the existing knowledge base by investigating the association between being NEET and prevalence of poor self-perceived health, mental health problems and pain.

In 2016 , a total of $9.7 \%$ young people between 18 24 years old were registered as NEETs in Norway, whereas the average proportion of NEETs in OECD countries amounted to $15.3 \%$ [7]. The European Foundation for the Improvement of Living and Working Conditions (Eurofound) has identified five main cate- gories of NEETs: the conventionally unemployed, the unavailable, the disengaged, voluntary NEETs and opportunity seekers [8]. This categorization indicates that NEETs are a highly heterogenic population which includes both vulnerable and non-vulnerable young people with varying degree of control over their own situation. In Norway, young people who are entitled to training but not enrolled in school or in paid employment are followed up by a special advisory service called 'Oppfølgingstjenesten' (OT). NEETs are categorized in different sub-groups by the OT service, and one of these sub-groups include those that are too ill to benefit from education, training or employment due to physical or mental illness, substance use, social and/or emotional problems. They may also be in an institution like hospital, jail, child protection units or other institutions. Data have shown that the proportion of young NEETs registered in this category by the OT service have doubled nationwide over the last six years [9]. In 2017, the southern part of Norway had the largest proportion of young people in the OT service's target group who were categorised as ill/institutionalised 
(21.1\% in Aust-Agder and $17.5 \%$ in Vest-Agder), which is significantly above the national average $(10.5 \%)$ [9]. The reasons for this increase are not known, but it suggests that the proportion of NEETs with health problems has increased.

International research has also confirmed a higher prevalence of chronic health problems among those who fail to complete upper secondary school when compared to those who have completed upper secondary education [10]. In a study based on data from the European Social Survey, NEETs reported to have poorer health than their peers who were employed or studying, and those NEET youth who were designated as 'disengaged' (unemployed, wanting a job but not actively looking for a job) reported the poorest health of all [11]. A longitudinal study has also shown a higher prevalence of mental health problems in NEET youth, and that suffering from mental health issues was a predictor of NEET status [12]. These findings were partly corroborated by a recent British study that found a higher prevalence of mental health problems in NEET youth when compared to their peers [13]. The latter study showed that even though nearly $60 \%$ of the NEET youth reported to have suffered from at least one mental health problem in their earlier years, the association between mental health and affiliation with the labour market or educational system was independent of previous mental health issues [13]. An Australian longitudinal study also found that NEET status among young people was associated with persistent, common mental disorders [14]. A Canadian study, on the other hand, showed that NEET youth and young people who are in school or employed are equally likely to suffer from internalising and externalising mental problems [15].

Pain might be a symptom that interferes considerably with school performance and might precede more complex mental and physical health problems. Although few studies have investigated the prevalence of pain in NEET youth, an OECD-study found no differences in physical pain or chronic health ailments between Latvian job-seeking NEET youth and youth who were gainfully employed or studying. In the inactive NEET group the prevalence of chronic mental problems, chronic health ailments, physical limitations and physical pain was higher than among young people who were studying or employed [16].

Systematic differences in health and school attendance according to socioeconomic status has also been reported, including a study among Norwegian and American adolescents which showed that those from lower educated and lower income families reported poorer health, which negatively impacted their likelihood of graduating from high school [2]. A systematic review has also reported that 52 out of 55 studies showed an inverse association between socioeconomic status and mental health problems in childhood and adolescence [17]. Further, a study has shown that Norwegian men and women with university or college education were expect to live 6.4 and 5 years longer than those with lower secondary education, respectively [18]. Although socioeconomic differences may cause health problems in unemployed populations [5], socioeconomic background may also partly influence high school completion through adolescents' health [2]. However, it has been found that health problems are increased in socially excluded groups such as NEETs independent of socioeconomic background [1]. This illuminates the complexity of the relationship between socioeconomic status, health and attainment to school and labour market.

To develop services that may help young NEETs returning to training or employment, it is also essential to have knowledge about the health and living conditions of the target group. Therefore, the objective of this study is to investigate the prevalence of poor selfperceived health, mental health problems and pain among young people who are not in education, employment or training, when compared to adolescents who attend school.

\section{MATERIAL AND METHOD}

This study is based on two cross-sectional surveys: 'Health, living conditions and lifestyles among young people who are not in education, employment or training' (hereafter referred to as the HELLAS study) and the Young Data study in Agder, which is part of the national Young Data study among young people in upper secondary schools. The target groups were adolescents registered as NEET by the OT service (the HELLAS-study) and an age- and gender matched reference group (the Young Data study) of adolescents attending high school in the south of Norway (Vestand Aust-Agder county). Both studies were conducted during the spring 2016, and data were collected using an online self-report questionnaire to assess selfperceived health, mental health problems, and pain. Oral and written information about the studies and instructions on how to fill out the questionnaire were provided before filling out the questionnaires. Written information was also provided to parents of adolescents under the age of 16 with the opportunity to refuse participation in these studies. Participation was completely voluntary, and participants could withdraw at any time during or after data collection. After written consent was obtained, the participants used approximately 20-45 minutes to complete the questionnaires. All responses were treated anonymously. The study was approved by the South-East Regional Committee for Medical and Health Research Ethics (REK case no. 2015/2431).

\section{Samples}

\section{The HELLAS study}

The administration in Norwegian counties is responsible for high school services and offering follow-up services for all those who not apply for high school or 
quit school before completion. All NEETs between 1621 years old are registered by the OT-services and categorized into subgroups. Some groups include vulnerable NEET youth at risk of marginalization, while others are defined as 'voluntary NEET' and are for example engaged in travelling and/or artistic activities for the purposes of self-realization. Our target group consists of vulnerable NEET youth who 1) have not applied for upper secondary education, 2) have turned down a grad school offer, 3) have quit before finishing compulsory training, 4) is unemployed or 5) has lost the right to education due to expulsion or termination of the contract. Thus, it focuses on the 'youth at risk' who lack access to learning opportunities and are jobless and/or inactive. In February 2016, the OT services in Agder county had registered 685 young people in the target group. The people in this group, who were in contact with the OT services in the period MarchJune 2016 for other reasons, were invited to participate in the study. In addition, everybody in the target group received a letter with information and an invitation, and Kristiansand municipality mobilised several services to invite the target group to participate in the study. Not all in the target group were in contact with the OT-service in the data collection period and did therefore not receive a face-to-face invitation. In addition, those who had recently applied for high school this year (deadline 1st of March 2016), were probably underrepresented in the study. In total, 105 young people from the NEET group completed the questionnaire over the course of the data collection period.

The Young Data study in Agder

In March 2016, the Young Data study in Agder was implemented in all junior high schools (13-16 years old) and in the first year of all high schools (16-17 years old) located in Aust- and Vest-Agder county (for more information on Young Data, see Ungdata.no). In addition, a strategic sample (based on the size of the municipality, specialisation and geography) of 500 students in the second and third grade of upper secondary were invited to participate. Thus, a total of $15651 \mathrm{stu}-$ dents participated in the Young in Agder 2016 study during school hours; 11042 (90\%) junior high students and 4609 (80\%) high school students, respectively. The present study, however, only used data provided by high school students.

\section{Final sample $(n=480)$}

The final sample in the present study was based on an individual matching process in order to balance the samples from the two cross-sectional studies according to age and gender. As increasing the number of controls up to a ratio of about $4 / 1$ has been shown to improve the power of a study [19], a total of 96 cases from the NEET group was matched with 384 participants from the reference group. Matching was performed using case-control matching procedure in SPSS, and matching tolerance was set to 0 .

\section{Measurement instruments}

The participants were asked how often they had suffered from the following symptoms over the last month: headache, neck and shoulder pain, joint and muscle pain, and abdominal pain. Response categories were 'never', 'sometimes', 'frequently' and 'every day', and the variables were dichotomised into 'never/ sometimes' vs. 'frequently/every day'. In addition, we used these to construct an aggregate measure in which the outcomes for one or more of the dichotomous variables 'headache', 'neck and shoulder pain', joint and muscle pain' were combined into 'sometimes/seldom tension pain' vs. 'frequently/daily tension pain'.

The participants reported their self-perceived health by answering the question 'How satisfied or dissatisfied are you with various aspects of your life?', in which 'Your health' was one of the sub-questions. Response categories were 'very dissatisfied', 'somewhat dissatisfied', 'neither dissatisfied nor satisfied', 'somewhat satisfied' and 'very satisfied'. These formed the basis for a dichotomous variable of "poor self-perceived health (very/somewhat dissatisfied) vs. neither/nor or somewhat/very satisfied.

The questionnaire contained a short version of the question battery in the Hopkins Symptom Checklist (HSCL-10) which measured psychological distress [20]. Items derived from this checklist include information about the following symptoms during the previous week; suddenly scared for no reason, feeling fearful, feeling faintness, dizziness or weakness, feeling tense or keyed up, blaming yourself for things, having trouble falling asleep or staying asleep, feeling blue, feeling everything is an effort and feeling hopeless about the future. Each item was rated on a scale from 1 (not at all) to 4 (extremely). Further, an average scale-score for all ten items was calculated, and Cronbach's Alpha for the included items were .93. As a previously published study has shown that average scores equal to or greater than 1.85 predict mental health distress among 16-24 year olds [21], the results were dichotomized into $<1.85 \mathrm{vs} \geq 1.85$.

The explanatory variable was constituted by NEETs (HELLAS respondents) vs high-school students (Young Data respondents, ref).

Parents' level of education was identified by asking whether the mother or father respectively had completed university or university college education.

Gender was in Young-data retrieved by asking whether participants were male or female. In the Hellas-Study, an additional question was added with the option of defining oneself as something other than male or female. This latter was not included due to low $\mathrm{n}$ in the group and the lack of this category in Youngdata.

In the HELLAS study, 'age' was defined by asking the young respondents to place themselves in two-year age categories (16-17, 18-19, 20-21 and 22 years and older). As this study included few participants in the 
Table 1. Differences in health problems and background characteristics between adolescents not in education, employment or training (NEET) and their in-school peers, stratified by gender.

\begin{tabular}{|c|c|c|c|c|c|c|}
\hline \multirow[b]{2}{*}{ Variables } & \multicolumn{3}{|c|}{ Girls } & \multicolumn{3}{|c|}{ Boys } \\
\hline & $\begin{array}{l}\text { NEET } \\
(n=43)\end{array}$ & $\begin{array}{c}\text { In school } \\
(n=172)\end{array}$ & p-value* & $\begin{array}{l}\text { NEET } \\
(\mathrm{n}=53)\end{array}$ & $\begin{array}{c}\text { In school } \\
(\mathrm{n}=212)\end{array}$ & p-value* \\
\hline \multicolumn{7}{|l|}{ Pain } \\
\hline Headache, \% (n) & $58(25)$ & $48(81)$ & 0.245 & $24(12)$ & $17(35)$ & 0.278 \\
\hline Neck and shoulder pain, \% (n) & $47(20)$ & $32(53)$ & 0.078 & $25(12)$ & $18(36)$ & 0.318 \\
\hline Joint and muscle pain, \% (n) & $33(14)$ & $25(41)$ & 0.248 & $22(11)$ & $15(29)$ & 0.212 \\
\hline Tension pain, aggregate, $\%(n)$ & $74(32)$ & $56(94)$ & 0.025 & $40(20)$ & $28(56)$ & 0.086 \\
\hline Abdominal pain, \% (n) & $45(19)$ & $26(43)$ & 0.013 & $16(8)$ & $11(22)$ & 0.317 \\
\hline Poor self-perceived health, $\%$ (n) & $71(29)$ & $45(73)$ & 0.003 & $60(30)$ & $38(74)$ & 0.005 \\
\hline Poor mental health, \% (n) & $74(31)$ & $54(92)$ & 0.023 & $47(24)$ & $28(58)$ & 0.010 \\
\hline \multicolumn{7}{|l|}{ Age } \\
\hline $16-17$ years, \% (n) & $28(12)$ & $28(48)$ & & $9(5)$ & $9(20)$ & \\
\hline $18-19$ years, \% (n) & $47(20)$ & $47(80)$ & & $68(36)$ & $68(144)$ & \\
\hline$\geq 20$ years, $\%(\mathrm{n})$ & $26(11)$ & $26(44)$ & 1.000 & $23(12)$ & $23(48)$ & 1.000 \\
\hline \multicolumn{7}{|l|}{ Parents' education } \\
\hline Low education, father, \% (n) & $71(27)$ & $55(87)$ & 0.074 & $75(36)$ & $54(100)$ & 0.007 \\
\hline Low education, mother, $\%(n)$ & $74(31)$ & $52(82)$ & 0.011 & $74(36)$ & $48(91)$ & 0.001 \\
\hline
\end{tabular}

Chi-square test

*Significance level $\mathrm{p}<0.05$.

oldest age group (as the target group for the OT-service is $16-21$ years), this group was merged with the group of participants between 20 and 21 years old $(\geq 20$ years). Similar categories were used in the Young Data study in order to match participants according to age.

\section{Statistical analyses}

We conducted initial descriptive analyses to obtain an overview of the material (Table 1). We used multivariable logistic regression to investigate differences in health between young people inside and outside the educational system, stratified by gender, controlled for mother's and father's education. The results of the multivariable analyses are presented in the form of odds ratios (OR), 95\% confidence intervals and $\mathrm{p}$ values (Table 2). We also tested alternative cut-off values in order to confirm that the direction of our results did not change. The level of statistical significance was set to $5 \%$. All analyses were conducted using IBM SPSS Statistics 24.0.

\section{RESUltS}

Unadjusted bivariate analyses showed that when compared to young people who attended school, more boys and girls who were not in education or employment reported poor self-perceived health (girls $71 \%$ vs. $45 \%, \mathrm{p}=0.003$; boys $60 \%$ vs. $38 \%, \mathrm{p}=0.005$ ) and poor mental health (girls $74 \%$ vs. $54 \%$, $\mathrm{p}=0.023$; boys $47 \%$ vs. $28 \%, \mathrm{p}=0.010$ ). Compared to girls who were in the school system, girls who were not in education or employment more frequently reported to suffer from tension pain (an aggregate measure of headaches and pains in the arms and legs) $(74 \%$ vs. $56 \%, p=0.025)$ and abdominal pain $(45 \%$ vs. $19 \%, \mathrm{p}=0.013)$. The study found no differences in any form of tension pain or abdominal pain between boys who were inside or outside the educational system.

Multivariable analyses, adjusted for parents' level of education, confirmed that more girls who were not in education or employment reported poor selfperceived health (OR 3.2; 95\% CI 1.4-7.5) and poor mental health $(2.4 ; 1.0-5.2)$ when compared to girls who were attending school. For boys, these correlations were no longer significant when parents' level of education were considered. Nor did the study find any significant associations between school affiliation and the individual variables of headaches, neck and shoulder pain, joint and muscle pain, tension pains in general or abdominal pain for either boys or girls.

\section{DiscuSSION}

The present study provides new and important knowledge about the health challenges in one of society's most vulnerable groups, as young people who are not in education or employment face very limited opportunities in the labour market and are at an increased risk of receiving disability benefits, poorer living conditions and poor future health.

Results from this study showed that poor selfperceived health and mental health problems were more common among girls who were not in education, employment or training when compared with girls in school, after adjustment for parents' level of education. Unadjusted analyses indicated that boys outside of upper secondary school have poor self-perceived physical and mental health when compared to boys who are attending school, but this correlation was no longer significant when the parental educational level 
Table 2: Associations between school affiliation and health ailments, stratified by gender, controlled for parents' education.

\begin{tabular}{|c|c|c|c|}
\hline \multirow[b]{2}{*}{ Outcome } & & Girls & Boys \\
\hline & & OR (CI 95\%) & OR (CI 95\%) \\
\hline \multirow[t]{3}{*}{ Headache } & NEET & $1.2(0.6-2.5)$ & $1.4(0.6-3.2)$ \\
\hline & Low education, father ${ }^{\mathrm{a}}$ & $2.5(1.1-4.9)^{*}$ & $1.6(0.6-3.2)$ \\
\hline & Low education, mother ${ }^{\mathrm{a}}$ & $0.8(0.4-1.7)$ & $0.8(0.4-1.8)$ \\
\hline \multirow[t]{3}{*}{ Neck and shoulder pain } & NEET & $1.6(0.7-3.3)$ & $0,9(0.4-2.2)$ \\
\hline & Low education, father ${ }^{\mathrm{a}}$ & $1.0(0.4-2.2)$ & $1.6(0.7-3.7)$ \\
\hline & Low education, mother ${ }^{\mathrm{a}}$ & $1.7(0.7-3.7)$ & $1.8(0.8-4.2)$ \\
\hline \multirow[t]{3}{*}{ Joint and muscle pain } & NEET & $1.0(0.5-2.4)$ & $1.5(0.6-3.7)$ \\
\hline & Low education, father ${ }^{\mathrm{a}}$ & $0.7(0.3-1.6)$ & $1.1(0.5-2.5)$ \\
\hline & Low education, mother ${ }^{\mathrm{a}}$ & $1.9(0.8-4.5)$ & $0.9(0.4-2.1)$ \\
\hline \multirow[t]{3}{*}{ Tension pain, aggregate } & NEET & $2.1(0.9-4.7)$ & $1.4(0.7-2.9)$ \\
\hline & Low education, father ${ }^{\mathrm{a}}$ & $1.6(0.7-3.3)$ & $1.6(0.8-3.2)$ \\
\hline & Low education, mother ${ }^{\mathrm{a}}$ & $0.9(0.4-1.9)$ & $1.0(0.5-2.0)$ \\
\hline \multirow[t]{3}{*}{ Abdominal pain } & NEET & $2.0(0.9-4.4)$ & $1.2(0.4-3.1)$ \\
\hline & Low education, father ${ }^{\mathrm{a}}$ & $1.0(0.5-2.4)$ & $2.6(0.8-8.7)$ \\
\hline & Low education, mother ${ }^{\mathrm{a}}$ & $1.2(0.5-2.8)$ & $2.4(0.8-7.3)$ \\
\hline \multirow[t]{3}{*}{ Poor self-perceived health } & NEET & $3.2(1.4-7.5)^{* *}$ & $1.9(1.0-4.0)$ \\
\hline & Low education, father ${ }^{\mathrm{a}}$ & $2.3(1.0-5.0)$ & $2.4(1.2-4.7)^{*}$ \\
\hline & Low education, mother ${ }^{\mathrm{a}}$ & $0.9(0.4-2.0)$ & $1.5(0.8-2.9)$ \\
\hline \multirow[t]{3}{*}{ Poor mental health } & NEET & $2.4(1.0-5.2)^{*}$ & $2.0(1.0-4.1)$ \\
\hline & Low education, father ${ }^{\mathrm{a}}$ & $0.8(0.4-1.6)$ & $1.3(0.6-2.6)$ \\
\hline & Low education, mother ${ }^{a}$ & $1.3(0.6-2.7)$ & $1.3(0.7-2.7)$ \\
\hline
\end{tabular}

${ }^{\mathrm{a}}$ Compared to mother/father with higher education

$* \mathrm{p}<0.05 * * \mathrm{p}<0.01$

was considered. Unadjusted analyses also showed a higher prevalence of general tension pain and abdominal pain among girls, but not among boys, who were not in education or employment when compared to young people who were attending school. However, these differences disappeared after statistical adjustments confirming that parents' level of education was an important confounder for the association between NEET status and prevalence of pain.

Whereas our findings revealed poorer self-perceived health among NEET girls, but not boys, results from the European Social Survey showed that being disengaged young men, but not women, increased the risk of reporting poor health compared with those being conventionally employed [11]. Females, however, reported a high degree of poor health regardless of employment status [11]. As far as we are aware, no other studies have assessed potential gender differences in terms of poor health among NEET youth when compared to young people who are attending school.

In contrast to our findings, the results from a longitudinal study among young Swiss men indicated that poor mental health predicts the likelihood of being outside education or employment [12]. A cohort study with a follow-up period of nine years has also shown that men, but not women, who had suffered from longterm mental health problems at the age of 11 to 19 had a significantly heightened risk of being outside education and employment later in life [22]. A comprehensive British cohort study confirmed that the correlation between the educational and employment situation and present mental health challenges was unrelated to challenges associated with the state of mental health in early childhood and adolescence [13]. The latter study did not report, however, whether these results applied to both genders.

Our findings showed no significantly heightened risk of pain among NEET youth when compared to youth who are attending school. To our knowledge, only one study, published by the Organization for Economic Cooperation and Development (OECD), has previously assessed the prevalence of pain among NEET Youth [16]. The result from this Latvian study showed an increased prevalence of pain among disengaged NEET youth, but not among NEET youth who were jobseekers [16]. On the other hand, numerous published studies have described health ailments among school youth. A Norwegian study showed a significantly higher prevalence of headaches, neck pain, back pain and abdominal pain among girls when compared to boys [23], and many other studies have confirmed the higher prevalence of subjective health ailments among girls when compared to boys [24,25]. Ravens-Sieberer and collaborators [26] have also reported that the gender differences in subjective health ailments in children and adolescents increase with age, and researchers have identified an inverse correlation between health ailments and socioeconomic status. Moreover, studies have shown a clear correlation between low self-esteem and high levels of stress and subjective 
health ailments $[23,24,27]$. Even though most of the studies mentioned above focus on youth who are in education, we believe there is reason to assume that young people who are not in education or employment may have just as low self-esteem, high levels of stress and health problems. This assumption rests on the observation that NEET youth more frequently have adverse life experiences as well as fewer resources and poorer living conditions than their peers, on top of their own, their parents' and society's expectations that they should change their educational or employment status [28]. However, further studies are needed to help confirm this assumption.

The higher prevalence of health problems among youth who are not in education or employment may possibly be explained by reference to previous reports of a higher degree of risk behaviour in this group, such as daily smoking, use of cannabis, hazardous alcohol consumption and low levels of physical activity (15). In addition, more young people in this group are underweight, overweight or obese when compare to youth in upper secondary schools [13,29].

The most important strength of the present study is that it provides valuable information which contributes to fill the existing knowledge gap concerning health problems among NEET youth. This information ought to be closely considered in the efforts to develop measures against school attrition and interventions that could help this group return to school or employment as quickly as possible. One of the reasons why few previously published studies have assessed health status among NEET youth may be that this group was particularly difficult and time-consuming to reach compared to high school students. Most likely, the valuable partnership that we established with the follow-up services which provided face-to-face invita- tion to the target group resulted in an increased participation rate among NEET youth in the present study. However, this approach may also have limited the representability of the NEET sample as only those who were in contact with the OT-service during the data collection period received a face-to-face invitation to participate in the present study. Furthermore, we acknowledge that the group of NEET youth participating in the present study may not be representative for all NEETs in other countries. Another well-known limitation of cross-sectional studies is that the design does not allow for causal interference.

\section{CONCLUSION}

The present study has provided new knowledge about health problems among NEET youth in Norway: poorer self-perceived health and poorer mental health was shown among girls who are outside of education and employment compared to girls in high school. As expected, our results also confirm lower socioeconomic status among NEET youth compared to their peers in school which partly may explain differences in health status. Future studies should be designed to identify factors that cause health problems among NEET youth and thereby providing a basis for developing methods and strategies which increase the likelihood of returning to school or employment.

\section{ACKNOWLEDGEMENTS}

We are grateful to all the adolescents who participated in the present study. We also thank the Norwegian Social Research (NOVA), the southern regional Drug and Alcohol Competence Center (Korus), the special advisory service for NEET youth, 'Oppfølgingstjenesten' (OT), and the participating municipalities for their contributions to the data collection.

\section{REFERENCES}

1. De Ridder KA, Pape K, Johnsen R, Holmen TL, Westin S, Bjørngaard JH. Adolescent health and high school dropout: A prospective cohort study of 9000 Norwegian adolescents (The Young-HUNT). PLoS One 2013; 8(9):e74954.

2. Sznitman SR, Reisel L, Khurana A. Socioeconomic background and high school completion: Mediation by health and moderation by national context. J Adolesc 2017;56:118-26.

3. De Ridder KA, Pape K, Cuypers K, Johnsen R, Holmen TL, Westin S, et al. High school dropout and longterm sickness and disability in young adulthood: a prospective propensity score stratified cohort study (the Young-HUNT study). BMC Public Health 2013;13:941.

4. Thern E, de Munter J, Hemmingsson T, Rasmussen F. Long-term effects of youth unemployment on mental health: does an economic crisis make a difference? J Epidemiol Community Health 2017;71(4):344-49.

5. Marmot M. Social determinants of health inequalities. Lancet 2005;365(9464):1099-104.

6. World Health Organization. Social determinants of health: The solid facts. 2nd Edition. 2003. Geneva: World Health Organization.

7. OECD. Education at a Glance 2017. OECD Indicators, OECD Publishing, Paris, 2017. http://dx.doi.org/ 10.1787/eag-2017-en.

8. Eurofound. Exploring the diversity of NEETs. Luxembourg: Publications Office of the European Union, 2016.

9. The Norwegian Directorate for Education and Training. Statistics portal (Statistikkportalen), 2018. https://statistikkportalen.udir.no/vgs/Pages/default.aspx. Accessed 28 Feb 2018. 
10. Vaughn MG, Salas-Wright CP, Maynard BR. Dropping out of school and chronic disease in the United States. Z Gesundh Wiss 2014;22(3):265-70.

11. Nordenmark M, Gådin KG, Selander J, Sjödin J, Sellström E. Self-rated health among young Europeans not in employment, education or training - with a focus on the conventionally unemployed and the disengaged. Society, Health \& Vulnerability 2015;6(1):25824.

12. Baggio S, Iglesias K, Deline S, Studer J, Henchoz Y, Mohler-Kuo M, et al. Not in education, employment, or training status among young Swiss men. Longitudinal associations with mental health and substance use. $J$ Adolesc Health 2015; 56(2):238-43.

13. Goldman-Mellor S, Caspi A, Arseneault L, Ajala N, Ambler A, Danese A, et al. Committed to work but vulnerable: Self-perceptions and mental health in NEET 18-year-olds from a contemporary British cohort. $J$ Child Psychol Psychiatry 2016;57(2):196-203.

14. Rodwell L, Romaniuk H, Nilsen W, Carlin JB, Lee KJ, Patton GC. Adolescent mental health and behavioural predictors of being NEET: a prospective study of young adults not in employment, education, or training. Psychol Med 2018;48(5):861-71.

15. Henderson JL, Hawke LD, Chaim G. Not in employment, education or training: Mental health, substance use, and disengagement in a multi-sectoral sample of service-seeking Canadian youth. Child Youth Serv Rev 2017;75:138-45.

16. OECD, Investing in Youth: Latvia. OECD Publishing, Paris, 2015. http://www.oecd.org/latvia/investing-inyouth-latvia-9789264240407-en.htm.

17. Reiss F. Socioeconomic inequalities and mental health problems in children and adolescents: A systematic review. Soc Sci Med 2013;90:24-31.

18. Steingrímsdóttir OA, Næss Ø, Moe JO, Grøholt EK, Thelle DS, Strand BH, et al. Trends in life expectancy by education in Norway 1961-2009. Eur J Epidemiol 2012;27(3):163-71.

19. Grimes DA, Schulz KF. Compared to what? Finding controls for case-control studies. Lancet 2005;365 (9468):1429-33.

20. Kleppang AL, Hagquist C. The psychometric properties of the Hopkins Symptom Checklist-10: a Rasch analysis based on adolescent data from Norway. Fam Pract 2016;33(6):740-5.

21. Strand BH, Dalgard OS, Tambs K, Rognerud M. Measuring the mental health status of the Norwegian population: A comparison of the instruments SCL-25, SCL-10, SCL-5 and MHI-5 (SF-36). Nord J Psychiatry 2003;57(2):113-8.

22. Veldman K, Reijneveld SA, Ortiz JA, Verhulst FC, Bültmann U. Mental health trajectories from childhood to young adulthood affect the educational and employment status of young adults: results from the TRAILS study. J Epidemiol Community Health 2015;69(6):588-93.

23. Aanesen F, Meland E, Torp S. Gender differences in subjective health complaints in adolescence: The roles of self-esteem, stress from schoolwork and body dissatisfaction. Scand J Public Health 2017;45(4):389-96.

24. Moksnes UK, Espnes GA. Stress, sense of coherence and subjective health in adolescents aged 13-18 years. Scand J Public Health 2017;45(4):397-403.

25. Wiklund M, Malmgren-Olsson EB, Ohman A, Bergström E, Fjellman-Wiklund A. Subjective health complaints in older adolescents are related to perceived stress, anxiety and gender - a cross-sectional school study in Northern Sweden. BMC Public Health 2012;12:993.

26. Ravens-Sieberer U, Torsheim T, Hetland J, Vollebergh W, Cavallo F, Jericek H, et al. Subjective health, symptom load and quality of life of children and adolescents in Europe. Int J Public Health 2009;54(2):151-9.

27. Murberg TA, Bru E. The role of neuroticism and perceived school-related stress in somatic symptoms among students in Norwegian junior high schools. J Adolesc 2007;30(2):203-12.

28. Lillejord S, Halvorsrud K, Ruud E, Morgan K, Freyr T, Fischer-Griffiths P, Frafall i videregående opplæring: En systematisk kunnskapsoversikt. Kunnskapssenter for utdanning: Oslo, 2015.

29. Stewart CH, Berry P, Przulj D, Treanor C. Cancer-related health behaviours of young people not in education, employment or training ('NEET'): a cross-sectional study. BMC Cancer 2017;17:165. 